Rabaska

Revue d'ethnologie de l'Amérique française

\title{
Chaire de recherche du Canada sur l'identité métisse (CRCIM)
}

\section{Denis Gagnon}

Volume 7, 2009

URI : https://id.erudit.org/iderudit/038393ar

DOI : https://doi.org/10.7202/038393ar

Aller au sommaire du numéro

Éditeur(s)

Société québécoise d'ethnologie

ISSN

1703-7433 (imprimé)

1916-7350 (numérique)

Découvrir la revue

Citer ce document

Gagnon, D. (2009). Chaire de recherche du Canada sur l'identité métisse

(CRCIM). Rabaska, 7, 302-303. https://doi.org/10.7202/038393ar d'utilisation que vous pouvez consulter en ligne.

https://apropos.erudit.org/fr/usagers/politique-dutilisation/ 


\section{OuEsT}

\section{Chaire de recherche du Canada sur l'identité métisse (CRCIM)}

Collège universitaire de Saint-Boniface

200, avenue de la Cathédrale

Saint-Boniface (Manitoba)

Téléphone : (204) 237-1818, poste 454

$\mathrm{R} 2 \mathrm{H} 0 \mathrm{H} 7$

Courriel : degagnon@ustboniface.mb.ca

\section{Faits saillants}

Les événements marquants de l'année 2008-2009 touchent le recrutement d'étudiants diplômés (Saskatchewan, Québec, France) ; la codirection de trois thèses de doctorat et d'un mémoire de maîtrise (Manitoba, Québec, France) ; la poursuite du développement d'un cadre théorique, conceptuel et méthodologique appliqué aux études métisses; et la diffusion des données aux plans national et international par le biais de nombreuses conférences publiques, de séminaires et de communications dans le cadre d'ateliers et de colloques.

\section{Diffusion}

Concernant la diffusion des données, un des événements les plus importants de l'année 2008-2009, l'ouvrage collectif bilingue, sous la direction de Denis Gagnon, Denis Combet et Lise Gaboury-Diallo, Histoires et identités métisses : Hommage à Gabriel Dumont / Métis Histories and Identities : A Tribute to Gabriel Dumont a été publié aux Presses universitaires de SaintBoniface. J'ai contribué à cet ouvrage avec « "Nous savons qui nous sommes". Les Métis et l'État canadien : définitions identitaires et agencéité ». Un autre chapitre, « De la dissimulation à la revendication identitaire : l'exemple des Métis francophones du Manitoba », est paru dans le collectif Autochtonies : vues de France et du Québec publié aux Presses de l'Université Laval sous la direction de Natacha Gagné, Thibault Martin et Marie Pineau-Salaün. Deux articles scientifiques ont également été publiés, il s'agit de « La Création des "vrais Métis" : définition identitaire, assujettissement et résistances » dans le numéro 13-14-15 de Port Acadie, Revue interdisciplinaire en études acadiennes, et de «L'Étude des langues métisses et les programmes de revitalisation du mitchif: un état de la situation », écrit en collaboration avec Suzanne Gagné dans Recherches amérindiennes au Québec, vol. 37, $\mathrm{n}^{\text {os }}$ 2-3.

En juin 2008, j'ai organisé le premier atelier sur les identités et cultures métisses au Centre de recherches d'histoire nord-américaine de l'Université Paris 1 - Panthéon-Sorbonne. Le second atelier a eu lieu au même endroit en juin 2009 et j'organise présentement le troisième qui devrait avoir lieu à Winnipeg en mai 2010. Chaque atelier a réuni une douzaine de chercheurs 
(étudiants et professeurs) et j'y ai présenté deux communications. J'ai été invité à présenter une communication dans le cadre du séminaire interdisciplinaire de la Chaire pour le développement de la recherche sur la culture d'expression française en Amérique du Nord (CEFAN) à l'Université Laval. J'ai également présenté deux communications au CusB, une dans le cadre des conférences de l'ACFAs-Manitoba et l'autre dans le cadre de la CusB/University of Vienna Joint Conference.

\section{Collaborations}

$\mathrm{Au}$ sujet des collaborations, je collabore avec Léonard Rivard dans le cadre de la subvention de l'ARUc sur les identités francophones de l'Ouest au Collège universitaire de Saint-Boniface (CUSB). Je collabore également avec plusieurs professeurs d'universités canadiennes : Jean-Guy Meunier (UQȦM), Robert Papen (UQÀM), avec Luc Noppen (UQÀM) dans le cadre du Forum canadien de recherche publique sur le patrimoine. Je suis membre régulier du Centre interuniversitaire d'études et de recherches autochtones (CIÉRA) de l'Université Laval et membre du conseil d'administration de la Fédération canadienne des sciences humaines (FCSH).

\section{Recherche}

L'année 2008-2009 a été particulièrement intéressante au plan de la recherche. Je suis cochercheur pour quatre projets, dont trois du CRSH. Il s'agit du projet d'Analyse thématique de documents textuels dirigé par Jean-Guy Meunier (UQÀm); de l'Alliance de recherche université communautés sur les identités francophones de l'Ouest, dirigé par Léonard Rivard (CusB), dont je suis responsable du volet métis, et du projet de Forum canadien de recherche publique sur le patrimoine, dirigé par Luc Noppen (UQÀm).

Denis GaGnon

\section{Centre canadien de recherche sur les francophonies en milieu minoritaire}

Institut français

Université de Régina

3737 Wascana Parkway

Régina (Saskatchewan) S4S 0A2
Téléphone : (306) 337-3273

Télécopieur : (306) 585-5183

Courriel : sophie.bouffard@uregina.ca

Le Centre canadien de recherche sur les francophonies en milieu minoritaire (CRFM) de l'Institut français dirige, de façon multidisciplinaire et interinstitu- 